\title{
Distribution of radionuclides in heterogeneous systems of mineral phases typical for crystalline rocks of the Russian underground research laboratory
}

ANASTASIIA A. RODIONOVA, IRINA E. VLASOVA AND VLADIMIR G. PETROV

Lomonosov Moscow State University

Presenting Author: skigirla@mail.ru

The project of the final repository for high-level radioactive waste in the exocontact zone of the Nizhnekansky granitoid massif is currently ongoing in Russia. To build a model of longterm radionuclides' migration it is necessary to evaluate their distribution onto surface of host rocks and contribution of individual mineral phases to the total sorption capacity of the rocks. The aim of this work is to determine the sorption efficiency of certain mineral phases in the heterogeneous systems. For this, we proposed a technique to determine the relative sorption efficiency (RSE), which characterizes the specific contribution of each mineral phase of a heterogeneous system to the sorption of radionuclides (Cs-137, Sr-90/Y-90, Am-241,243). The methodology for determining the RSE parameter is based on analysis of the spatial distribution of radionuclides determined by digital autoradiography together with the mineral phase analysis by scanning electron microscopy with energy dispersive X-ray spectroscopy. It was demonstrated that the RSE values (sorption efficiency) of different mineral phases of the certain rock sample differ only slightly (no more than 4 times). The predominant mineral phase for $\mathrm{Cs}, \mathrm{Sr} / \mathrm{Y}$ sorption under investigated conditions is chlorite with RSE values 2 and 1.8, respectively. Am was uniformly distributed onto mineral phases with close RSE values $(0,97-1)$.

We also performed experiments on radionuclides' competitive sorption on the crushed minerals (biotite and quartz for cesium) which were simultaneously present in the system. The experiments were carried out using dialysis cartridges, which provided a reliable separation of the two distinct minerals. The sorption experiments with only one mineral per system were performed for comparison. The sorption efficiency of mineral phases was different in "one-mineral" and "two-mineral" systems, e.g. distribution coefficient of cesium in the case of quartz was larger in the "one-mineral" system than in heterogeneous one.

This work was supported by the Russian Science Foundation (project 19-73-20051). 